\title{
Estabilidade da microestrutura e do teor de carotenóides de pós obtidos da polpa de pequi (Caryocar brasiliense Camb.) liofilizada
}

\author{
Stability of the microstructure and carotenoids contents of the freeze-dried pequi \\ (Caryocar brasiliense Camb.) pulp in the powdered form
}

\author{
Cibele Cristina de Oliveira ALVES ${ }^{1}$, Jaime Vilela de RESENDE ${ }^{1 *}$, \\ Rafael Souza Ribeiro CRUVINEL ${ }^{1}$, Mônica Elisabeth Torres PRADO ${ }^{1}$
}

\section{Resumo}

Pós obtidos a partir da polpa (mesocarpo interno) de pequi (Caryocar brasiliense Camb.) liofilizada, elaborados com adição de alcoóis (etanol e isopropanol), em concentrações de 0,5 e $10 \%$ e de açúcares (sacarose e frutose), em concentrações de 0,5 e $10 \%$, foram desenvolvidos neste trabalho. Análises microestruturais por microscopia fotônica dos pós de pequi liofilizados foram feitas para visualizar o grau de cristalinidade. Também foram feitas análises de cor usando colorímetro Minolta e dos teores de carotenóides totais por espectrofotometria. Os resultados mostraram que tratamentos constituídos da combinação de sacarose e etanol foram os que apresentaram formação de estruturas cristalinas e melhor preservação dos carotenóides. O teor de carotenóides nos pós obtidos da polpa de pequi liofilizada é mais bem preservado quanto maior for a concentração do álcool adicionado nos pré-tratamentos. Tratamentos com frutose e isopropanol produziram pós tipicamente amorfos, com ocorrência do fenômeno de caking. Pré-tratamentos com sacarose e etanol são os indicados para a produção de pós de pequi liofilizados com estabilidade físico-química e microestrutural.

Palavras-chave: pequi; pós alimentícios; microestrutura; carotenóides.

\begin{abstract}
In this study, food powders obtained from the freeze-dried pequi (Caryocar brasiliense Camb.) pulps (internal mesocarp) were developed by adding alcohols (ethanol and isopropyl alcohol) in concentrations of 0,5 , and $10 \%$ and sugars (sucrose and fructose) in concentrations of 0 , 5 , and $10 \%$. Microstructure analyses by photonic microscopy of the freeze-dried powders were used to evaluate the degree of crystallization. Color analyses using a Minolta colorimeter and the total carotenoid values using a spectrophotometer were also done. The results show that treatments with a sucrose and ethanol combination presented the formation of crystalline structures and the best preservation of the carotenoid contents. The higher the concentration of the alcohol added in the pre-treatments, the better preserved the caretenoids in the freeze- dried powders became. Treatments with fructose and isopropyl alcohol produced freeze- dried powders that were typically amorphous presenting caking phenomena. Pre-treatments with sucrose and ethanol are the solution to these problems since they are able to produce freeze-dried powders of the pequi pulp with physical chemical and microstructural stability.

Keywords: pequi; food powders; microstructure; carotenoids.
\end{abstract}

\section{Introdução}

O pequi (Caryocar brasiliense Camb.) é um fruto típico do Cerrado brasileiro com ampla utilização pelos sertanejos e todas as suas partes têm um emprego específico. De todos os usos, o de maior destaque é o do fruto, na alimentação. $\mathrm{O}$ grande consumo de pequi pelos sertanejos deve-se ao sabor e aroma peculiares e também pelo seu alto valor nutricional (MARQUES et al., 2001).

De modo geral, a sua floração se dá de agosto a novembro, coincidindo com o período das chuvas, com pico em setembro, já a frutificação ocorre de novembro a fevereiro (ALMEIDA et al., 1998). A sazonalidade é um fator que limita a comercialização e o acesso da população ao pequi.

A desidratação do pequi seria uma excelente alternativa para conservar e garantir o comércio do fruto em períodos de entressafra. A liofilização constitui um processo de desidratação em que a água do produto submetida ao prévio congelamento passa diretamente do estado sólido para o gasoso (sublimação), em condições especiais de temperatura e pressão. Para que isso ocorra, é necessário que a pressão de vapor e a temperatura da camada de gelo sublimável estejam abaixo do ponto tríplice da água. O vapor libertado pela sublimação é captado pelo condensador, que deve estar a uma temperatura mais baixa do que o produto a ser liofilizado (KING, 1988). Krokida e Philippoulous (2006) avaliaram os efeitos da secagem convencional e da secagem por liofilização no flavor de maçãs. Os resultados mostraram que a secagem por liofilização garantiu produtos com qualidade de flavor altamente superior àqueles secados por método convencional.

Recebido para publicação em 15/6/2007

Aceito para publicação em 14/12/2007 (002609)

${ }^{1}$ Departamento de Ciência dos Alimentos - DCA, Universidade Federal de Lavras - UFLA, CP 3037, CEP 37200-000, Campus Universitário, Lavras - MG, Brasil,

E-mail: jvresende@ufla.br

${ }^{*}$ A quem a correspondência deve ser enviada 
Segundo Ribeiro (2000), o pequi é um fruto rico em carotenóides, no qual foi encontrado o maior teor de vitamina $\mathrm{A}$, sendo este valor quase vinte vezes superior ao da cenoura e pupunha, e duas vezes superior ao do dendê. Os carotenóides evitam a formação de radicais livres no corpo e previnem tumores e o desenvolvimento de doenças cardiovasculares. Entretanto, os carotenóides são compostos extremamente susceptíveis às reações oxidativas, devido ao alto grau de insaturação das ligações. Nas frutas e hortaliças in natura, a estrutura celular e a complexação com proteínas lhes conferem certa estabilidade. Durante as várias etapas da desidratação, essa ultra-estrutura e os complexos podem ser quebrados, expondo os carotenóides a fatores adversos, levando-os à destruição. A estabilidade varia largamente no processamento e na estocagem, dependendo da temperatura, disponibilidade de oxigênio, exposição à luz, atividade de água, acidez, presença de metais e da própria estrutura (GODOY; RODRIGUEZ-AMAYA, 1998). Sendo assim, o emprego de técnicas de desidratação e adição de compostos que garantam a maior estabilidade dos carotenóides é extremamente importante para assegurar um produto final de qualidade e de boa aceitação no mercado.

A obtenção de pós comestíveis a partir da polpa do pequi (mesocarpo interno) permite a ampliação do comércio do fruto com a utilização do produto liofilizado em diversos nichos do mercado, como, por exemplo, a elaboração de temperos, bebidas, doces, dentre outros, gerando maior valor agregado ao alimento. Contudo, a liofilização provoca certas mudanças estruturais nos açúcares como o alto grau de amorfismo, tornando o produto altamente higroscópico e sensível às mudanças físicas, químicas e microbiológicas, as quais prejudicam a vida de prateleira e a estabilidade do produto.

O cristal constitui o estado mais estável, possuindo a menor energia livre, ou seja, a menor energia disponível (BUNN, 1972). Tal estado caracteriza-se por suas partes componentes (átomos, moléculas ou íons) estarem arranjadas nas chamadas redes espaciais, sendo as distâncias entre os átomos de um cristal, de quaisquer materiais, constantes e características dele. O processo de cristalização ocorre em duas etapas: nucleação e desenvolvimento do cristal, ou seja, o núcleo primeiro se forma e depois cresce, sendo que a força motriz desse processo é a supersaturação (GEANKOPLIS, 1998). Na primeira, ocorre uma condensação do material devido à colisão das partículas e, na segunda, verifica-se o aumento em tamanho do núcleo e a formação do cristal. Dessa forma, a adição de alguns solventes orgânicos, tais como alcoóis, antes do congelamento, reduz significativamente a solubilidade do açúcar constituinte e promove a sua cristalização pela supersaturação do sistema (ALMEIDA; CAL-VIDAL, 1997; SING et al., 1991, CARLOS; RESENDE; CAL-VIDAL, 2005). Uma alternativa para auxiliar na indução da cristalização seria através da adição de pequenos cristais de açúcares, que atuariam no processo de nucleação heterogênea (JANCIC; GROOSTSCHOLTEN, 1984). A adição de açúcares em pós de frutas liofilizados também tem a função de reter compostos aromáticos durante o processamento (ILLY; VIANI, 1996).

Sendo assim, o presente trabalho teve como objetivos principais: i) a obtenção de pós-liofilizados comestíveis a partir da polpa (mesocarpo interno) do pequi; ii) a caracterização dos pós obtidos da polpa de pequi liofilizada quanto ao teor de carotenóides e cor; e iii) análises dos efeitos da adição de alcoóis e açúcares anterior à etapa de congelamento sobre o grau de cristalização dos pós, através da visualização da sua microestrutura por técnicas de microscopia fotônica.

\section{Material e métodos}

\subsection{Preparo das amostras e tratamentos pré-congelamento}

Foram elaborados extratos contendo $30 \%$ de polpa (mesocarpo interno) do pequi, provenientes do município de Sete Lagoas (Brasil), adicionados de açúcares (frutose ou sacarose) e de alcoóis (etanol ou isopropanol), em concentrações de 0 , 5 e $10 \%$ (mL.100 $\mathrm{mL}^{-1}$ de extrato), tanto para os açúcares como para os alcoóis. Para completar as proporções dos extratos até volume de $40 \mathrm{~mL}$, adicionou-se água destilada. Os extratos foram homogeneizados, filtrados e colocados em placas de Petri de vidro com capacidade de $30 \mathrm{~mL}$ e submetidos a congelamento em ar estático em congelador (ultrafreezer REVCO, Asheville, EUA) com temperatura de $-60 \pm 2{ }^{\circ} \mathrm{C}$ para serem, em seguida, conduzidos a um liofilizador piloto (Liobras-L101, São Carlos, Brasil), operando com pressão de vácuo de 0,998 mbar. O tempo médio para a liofilização das amostras foi de 72 horas.

\subsection{Determinação da atividade inicial (aw) da polpa liofilizada}

A determinação da atividade inicial dos pós obtidos da polpa de pequi foi feita logo após a liofilização, usando um higrômetro de ponto de orvalho (Aqualab, Decagon. Modelo 3TE, Pullman, Washington, EUA).

\subsection{Análise do teor de carotenóides totais}

Nos pós obtidos a partir do mesocarpo interno do pequi, foram realizadas as análises de carotenóides totais. Os carotenóides totais foram extraídos com álcool isopropílico e hexano, sendo a leitura da cor feita num espectrofotômetro a $450 \mathrm{~nm}$, segundo normas do Instituto Adolfo Lutz (1985) com modificações. Os resultados foram expressos em $\mu \mathrm{g}$ de carotenóides por grama de pó de pequi liofilizado.

\subsection{Análise da cor}

A determinação dos parâmetros para análise de cor dos pós liofilizados foi feita usando um colorímetro (Minolta, modelo CR400, Konica Minolta Sensing, Inc., Japão) com a determinação no modo CIE L*a* $\mathrm{b}^{\star}$.

A coordenada $L^{*}$ representa quanto mais clara ou mais escura é a amostra, com valores variando de 0 (totalmente preta) a 100 (totalmente branca). A coordenada de cromaticidade $a^{*}$ pode assumir valores de -80 (verde) a +100 (vermelho) e a coordenada de cromaticidade $b^{*}$ pode variar de -50 (azul) a +70 (amarelo). A diferença de cor total $\left(\Delta \mathrm{E}^{*}\right)$ foi calculada de acordo com a Equação 1 abaixo:

$$
\Delta E^{*}=\left[\left(\Delta L^{*}\right)^{2}+\left(\Delta a^{*}\right)^{2}+\left(\Delta b^{*}\right)^{2}\right]^{0,5}
$$


As coordenadas $\mathrm{a}^{*} \mathrm{e} \mathrm{b}^{*}$ também foram usadas para calcular o $\mathrm{h}^{0}$ (ângulo da tonalidade) a partir da seguinte Equação 2 (MINOLTA, 1998):

$h^{0}=\tan ^{-1}\left(\frac{b^{*}}{a^{*}}\right)$

\subsection{Microscopia fotônica}

A análise por microscopia fotônica dos pós de pequi liofilizados, após diferentes tratamentos, foi feita por fotomicrografias das amostras visualizadas em um microscópio (MEIJI, ML5000 series, Meiji Techno, Japão) acoplado a um sistema de vídeo-captura.

\subsection{Delineamento experimental e análise estatística}

Os experimentos foram conduzidos seguindo uma estrutura fatorial com três repetições combinando os fatores açúcar e álcool. Os tratamentos que constituem o planejamento experimental são mostrados na Tabela 1.

$\mathrm{O}$ efeito dos tratamentos sobre o teor de carotenóides e parâmetros de cor $\left(\Delta \mathrm{E}^{*} \mathrm{e}\right.$ ângulo $\left.\mathrm{h}^{\circ}\right)$ dos pós de pequi liofilizados, em função das concentrações de açúcares e de álcool, foi avaliado por meio da análise de regressão não linear (modelo quadrático) e do método de superfície de resposta, sendo a seleção do ajuste feito baseada na melhor correlação $\left(\mathrm{r}^{2}\right)$, desvio padrão e $F$ estatístico, os quais foram obtidos com os softwares Statistica versão 7.0 (Statsoft ${ }^{\circledR}$ ) e Minitab 14.

\section{Resultados e discussão}

\subsection{Atividade de água (aw) inicial das amostras liofilizadas}

A Figura 1 apresenta os valores das atividades de água inicial dos pós de pequi medidos logo após o processo de liofilização.

Verifica-se que a adição do etanol no tratamento constituído de sacarose promoveu aumento na atividade de água inicial dos pós de pequi liofilizados, quando comparado aos adicionados de isopropanol. A justificativa é que o etanol em combinação com a sacarose está reduzindo a taxa de sublimação do gelo durante o processo de liofilização, devido à sua maior interação com a água através das fortes ligações de hidrogênio.

Tabela 1. Tratamentos que constituem o planejamento experimental (Combinação dos fatores 1 e 2).

\begin{tabular}{|c|c|c|}
\hline \multicolumn{2}{|c|}{ Fatores } & $\begin{array}{c}\text { Níveis } \\
\text { - Concentração (0\%) (-) }\end{array}$ \\
\hline 1 - Açúcar & Sacarose & $\begin{array}{l}\text { - Concentração (0\%) (-) } \\
\text { - Concentração }(5 \%)(0) \\
\text { - Concentração }(10 \%)(+)\end{array}$ \\
\hline & Frutose & $\begin{array}{l}\text { - Concentração (0\%) (-) } \\
\text { - Concentração (5\%) (0) } \\
\text { - Concentração (10\%) (+) }\end{array}$ \\
\hline \multirow[t]{2}{*}{2 - Álcool } & Etanol & $\begin{array}{l}\text { - Concentração (0\%) (-) } \\
\text { - Concentração (5\%) (0) } \\
\text { - Concentração (10\%) (+) }\end{array}$ \\
\hline & Isopropanol & $\begin{array}{l}\text { - Concentração (0\%) (-) } \\
\text { - Concentração (5\%) (0) } \\
\text { - Concentração (10\%) (+) }\end{array}$ \\
\hline
\end{tabular}
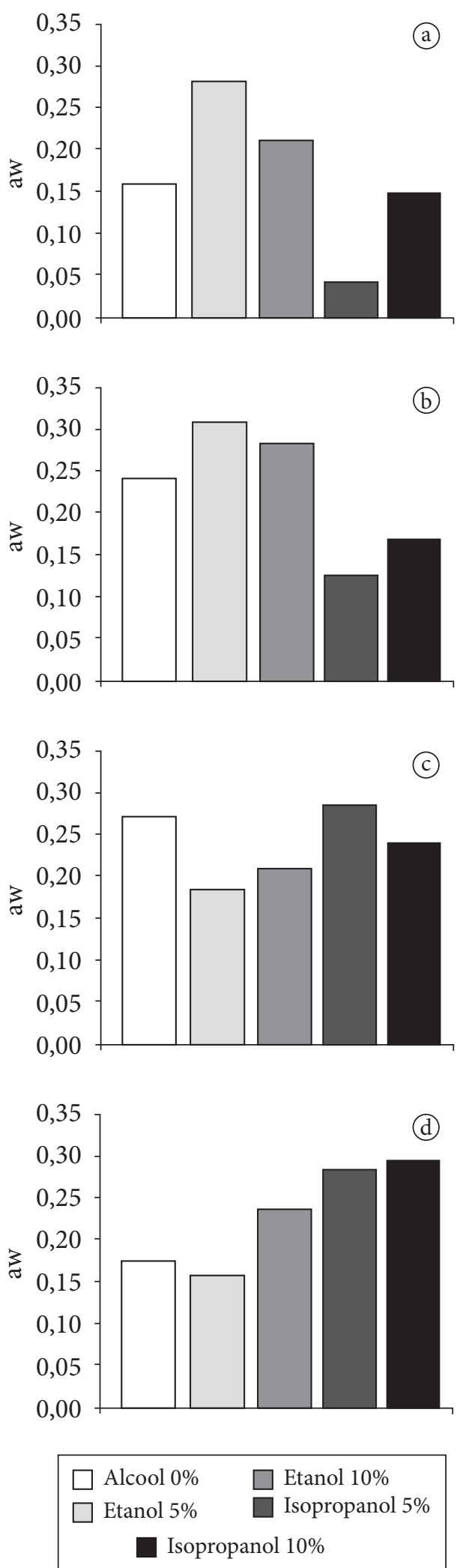

Figura 1. Atividade de água dos pós de pequi obtidos logo após o processo de liofilização para os tratamentos com açúcares adicionados de etanol e isopropanol. a) sacarose $5 \%$; b) sacarose $10 \%$; c) frutose $5 \%$; e d) frutose $10 \%$. 
Entretanto, observa-se comportamento adverso para os tratamentos com Frutose. Os valores da atividade de água inicial para os pós de pequi liofilizados tratados com frutose e adicionados de isopropanol foram os que apresentaram os maiores índices. Nestes tratamentos, observa-se que o alto grau de amorfismo nos açúcares acarreta, durante o processo de liofilização, a reestruturação e colapso das amostras, dificultando a retirada da água (MAIA, 1988).

\subsection{Análise do teor de carotenóides}

$\mathrm{Na}$ Figura 2, são mostradas superfícies de resposta obtidas após ajuste por regressão não linear (quadrática) dos resultados do teor de carotenóides totais dos pós obtidos da polpa de pequi liofilizada para os tratamentos com sacarose, em função da concentração de etanol (Figura 2a) e de isopropanol (Figura 2b).

Na Figura 3, são mostradas superfícies de resposta, obtidas pelo mesmo procedimento, do teor de carotenóides dos pós
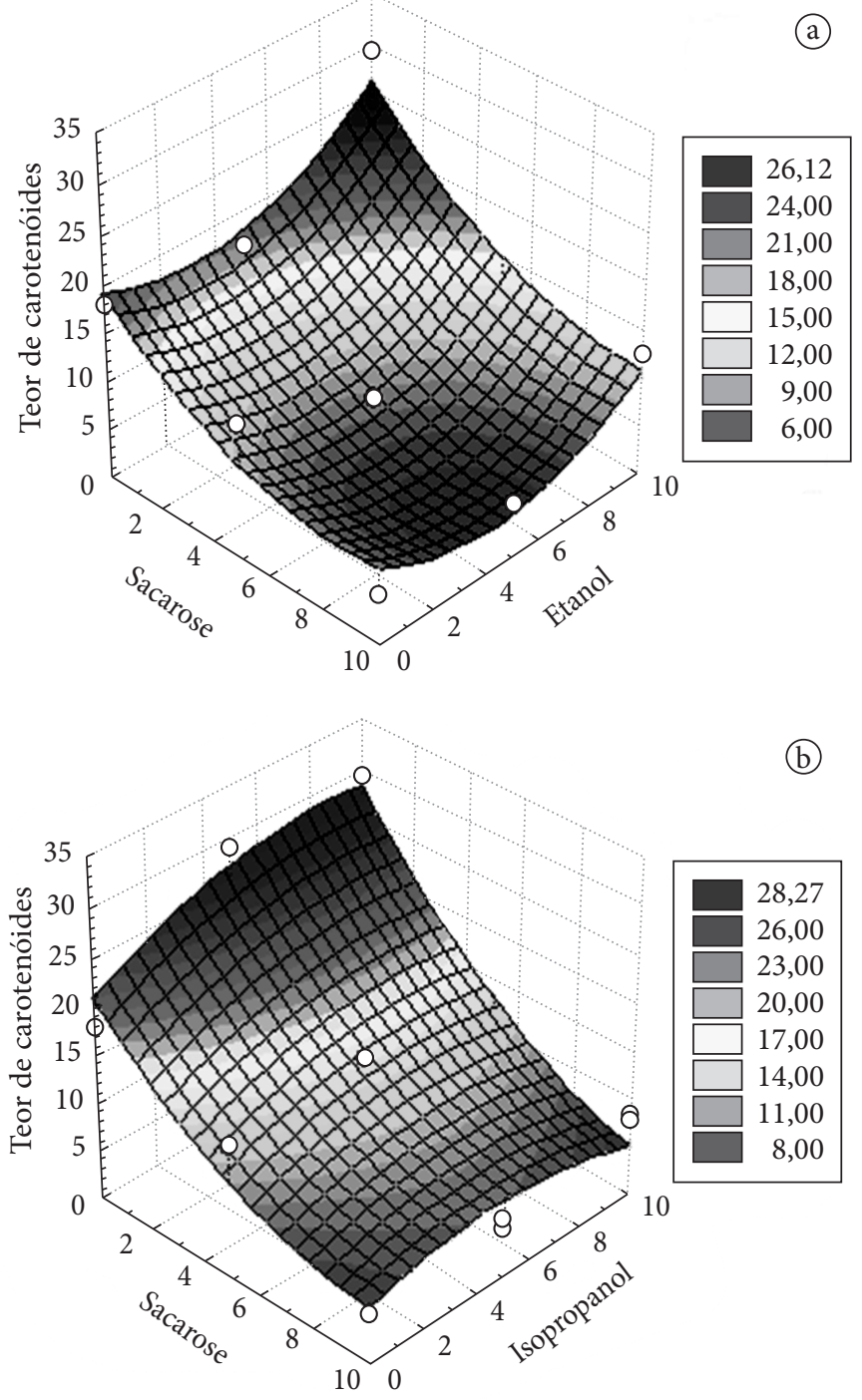

Figura 2. Superfícies de Resposta para os teores de carotenóides $\left(\mu \mathrm{g} \cdot \mathrm{g}^{-1}\right)$ dos pós de pequi liofilizados em função da concentração (\%) de sacarose e da concentração (\%) de: a) etanol $\left(\mathrm{r}^{2}=85,4 \%\right)$; e b) isopropanol $\left(r^{2}=90,5 \%\right)$. obtidos da polpa de pequi liofilizada em função da concentração de frutose e da concentração de etanol (Figura 3a) e de isopropanol (Figura 3b).

Para os sistemas sacarose-etanol (Figura 2a), os fatores sacarose $(\mathrm{p}<0,01)$, etanol $(\mathrm{p}<0,05)$ e interações $(\mathrm{p}<0,01)$ influenciaram significativamente o teor de carotenóides dos pós obtidos da polpa de pequi liofilizada. Para os sistemas sacaroseisopropanol (Figura $2 \mathrm{~b}$ ), os fatores significativos foram sacarose, isopropanol e interações $(\mathrm{p}<0,01)$. Já nos sistemas constituídos de frutose adicionados de etanol e isopropanol (Figuras $3 \mathrm{a} \mathrm{e} 3 \mathrm{~b}$ ), somente $\mathrm{o}$ fator frutose $\mathrm{e}$ as interações frutose $\mathrm{X}$ álcool foram significativos $(\mathrm{p}<0,01)$.

Observa-se, nas Figuras 2 e 3, que os maiores valores de teor de carotenóides foram encontrados para os tratamentos constituídos apenas de alcoóis, sem adição de açúcar. Nesses tratamentos, verifica-se que a concentração do álcool interferiu
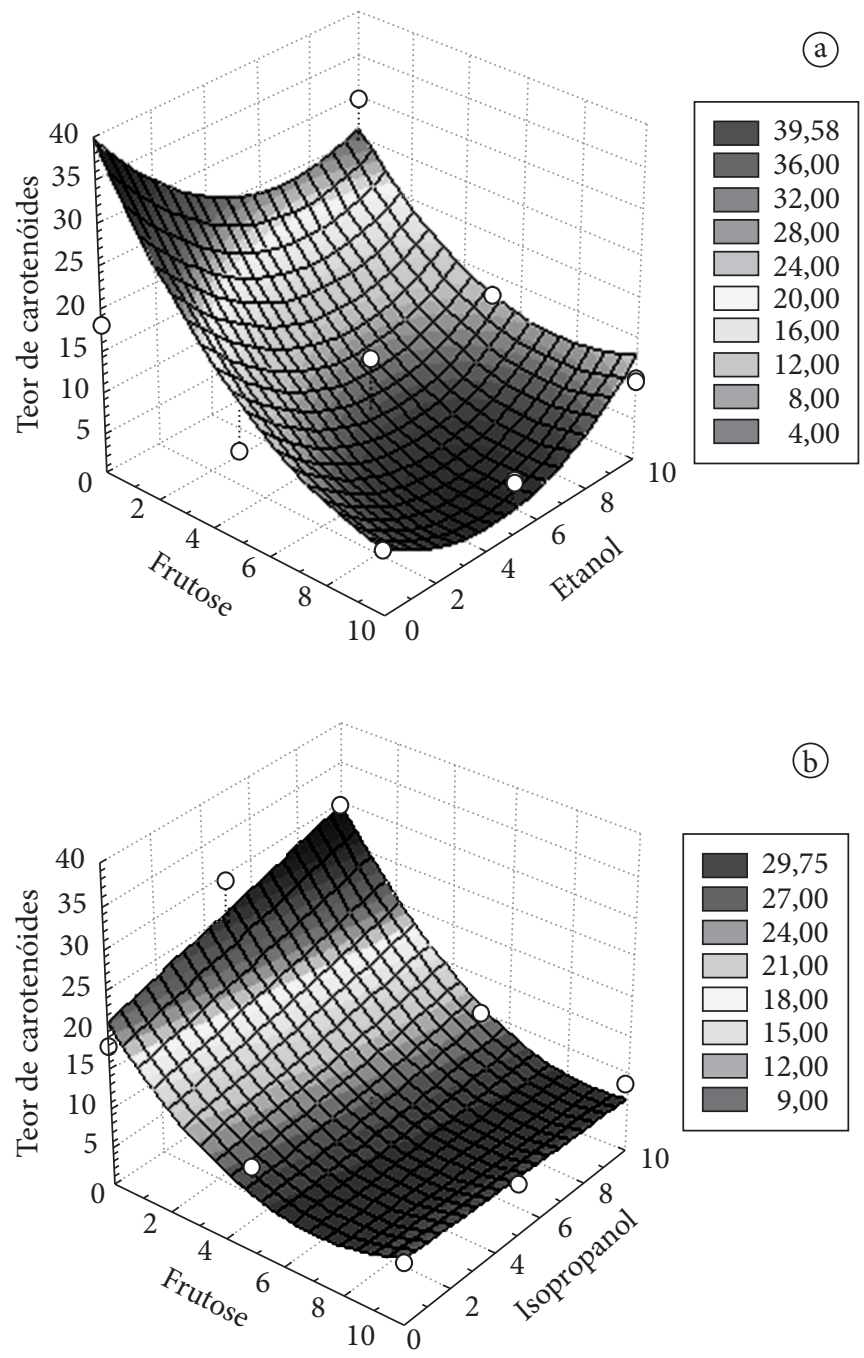

Figura 3. Superfícies de resposta para os teores de carotenóides $\left(\mu \mathrm{g} \cdot \mathrm{g}^{-1}\right)$ dos pós obtidos da polpa de pequi liofilizada em função da concentração (\%) de frutose e da concentração (\%) de: a) etanol $\left(r^{2}=89,8 \%\right)$; e b) isopropanol $\left(r^{2}=92,9 \%\right)$. 
na preservação dos carotenóides, apresentando resultados que variam proporcionalmente com a concentração do solvente.

Considerando o pré-tratamento como um processo de extração por solvente, os resultados mostraram que o álcool atua aumentando a eficácia na extração dos carotenóides. Por isso, quanto maior a concentração do álcool, maior será a sua interação com o carotenóide. Além disso, os alcoóis influenciam a estabilidade do pó obtido pelo processo de liofilização, evitando perdas provenientes do colapso estrutural. Assim, os resultados demonstram o efeito protetor dos alcoóis na elaboração dos extratos da polpa de pequi, antes do processo de liofilização. Com muito poucas exceções, carotenóides são insolúveis em água e solúveis em solventes orgânicos, tais como acetona, álcool, éter etílico, clorofórmio e acetato de etila (RODRIGUEZ-AMAYA, 2001).

Um comportamento diferente é observado nos tratamentos contendo açúcares (Figuras 2 e 3). O aumento das concentrações do açúcar nos pós de pequi liofilizado reduz os teores de carotenóides totais. O açúcar, além de contribuir para a formação de estruturas amorfas no processo de liofilização, o que gera instabilidade no produto e o torna mais vulnerável a reações degradativas, interage ou compete quimicamente com demais componentes do sistema prejudicando o processo de extração de carotenóides e interferindo nas leituras do espectrofotômetro.

Em estudo realizado por Shimizu et al. (2002), foi observado que caquis da variedade "Rama Forte", tratados com álcool, alcançaram médias de coloração bem próximas ao máximo, que descrevem frutos totalmente avermelhados, devido à predominância de carotenóides o que confirma a afinidade do álcool com estes compostos.

Durante os processos de desidratação ocorre perda de carotenóides totais e vitamina $\mathrm{A}$, em alimentos ricos nesses compostos. Mesmo a liofilização sendo um método de desidratação que visa à integridade funcional e sensorial do alimento, as perdas de carotenóides são fatores preocupantes neste processo. Qualquer que seja o método de processamento escolhido, a degradação de carotenóides aumenta conforme o tempo, a temperatura, o tamanho e a desintegração das partículas do alimento. Durante as várias etapas do processo de liofilização, a estrutura celular e os complexos dos alimentos podem ser quebrados, expondo os carotenóides a fatores adversos, levando-os à sua destruição. Devido ao aumento da superfície de contato e à diminuição da quantidade de água, o alimento fica mais exposto à ação de agentes externos, como o oxigênio. Isso ocorre, principalmente, se não houver uma estabilidade estrutural dos produtos obtidos. Reduzindo-se o tempo de processamento e a temperatura, e o tempo entre o descascamento, o corte ou a desintegração e o processamento, a retenção melhora significativamente. Dessa forma, processamento com baixa temperatura e menor tempo é uma boa alternativa (RODRIGUEZ-AMAYA, 1993).

\subsection{Cor}

As superfícies de resposta ajustadas por regressão não linear (quadrática) dos valores da diferença total de cor $\left(\Delta \mathrm{E}^{\star}\right)$ dos pós obtidos da polpa de pequi liofilizada em relação às amostras in natura em função das concentrações de sacarose e das concentrações de etanol estão mostradas na Figura 4a e, para os sistemas sacarose-isopropanol, na Figura 4b.

Na Figura 5, são apresentadas as superfícies de resposta para o parâmetro ângulo da tonalidade $\left(\mathrm{h}^{\circ}\right)$ na análise de cor dos pós obtidos da polpa de pequi liofilizada, em função da concentração de sacarose e das concentrações de etanol (Figura 5a) e isopropanol (Figura 5b).

Quanto maior o valor de $\Delta \mathrm{E}^{\star}$, maior a diferença total de cor do produto processado em relação ao produto original. Pela análise de variância, verifica-se que o fator concentração de sacarose $(\mathrm{p}<0,01)$ é o único que influencia significativamente o valor de $\Delta \mathrm{E}^{\star}$ dos pós de pequi. Estes resultados podem ser visualizados na superfície de resposta da Figura 4a. Os maiores valores de $\Delta \mathrm{E}^{\star}$ são obtidos com altas concentrações de sacarose e os menores com altas concentrações de etanol e se verifica maior preservação do teor de carotenóides.
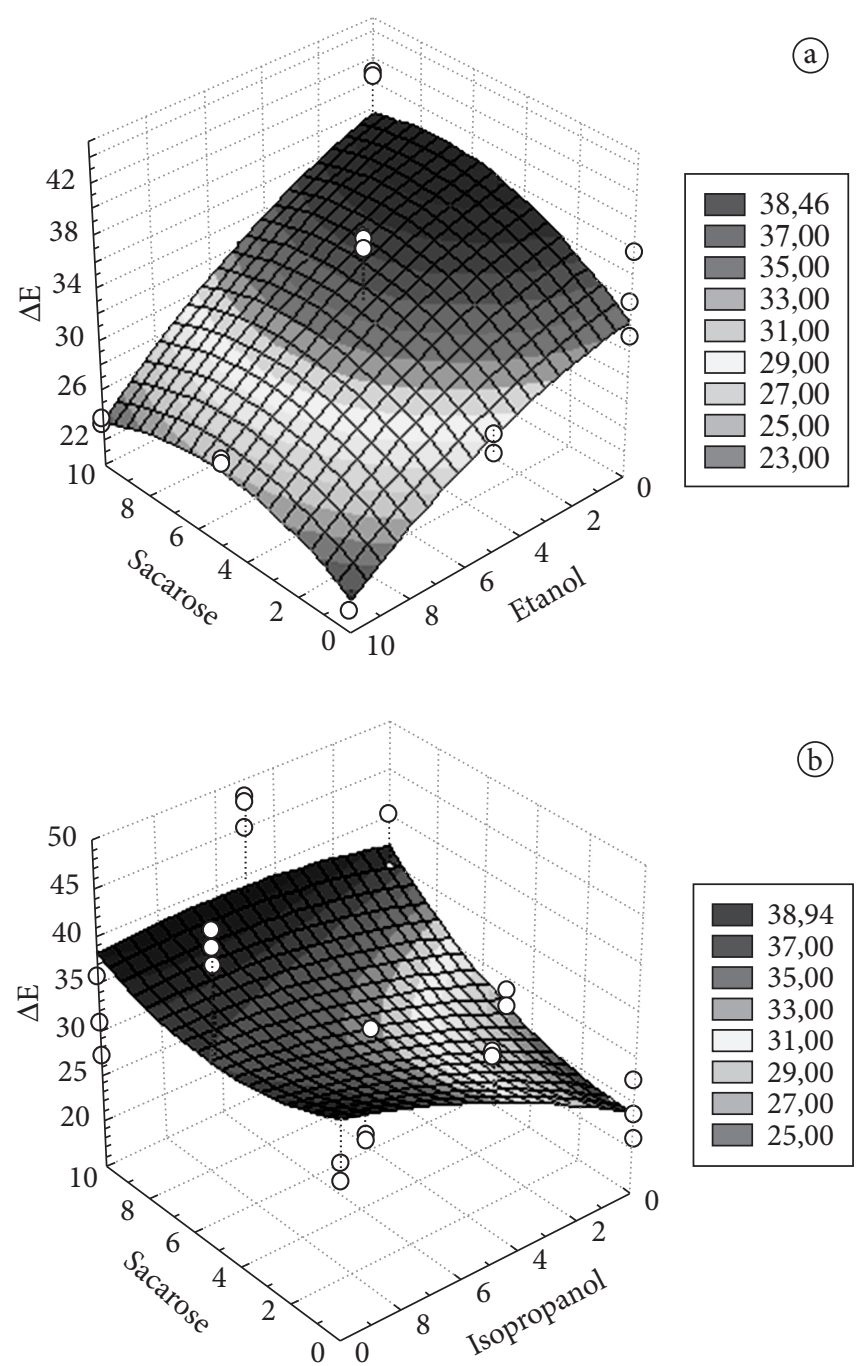

Figura 4. Superfícies de resposta para o parâmetro diferença total de cor $\left(\Delta \mathrm{E}^{\star}\right)$ em relação ao fruto in natura da análise de cor dos pós obtidos da polpa de pequi liofilizada em função da concentração de sacarose e da concentração de: a) etanol $\left(r^{2}=77,1 \%\right)$; e b) isopropanol $\left(r^{2}=30,1 \%\right)$. 

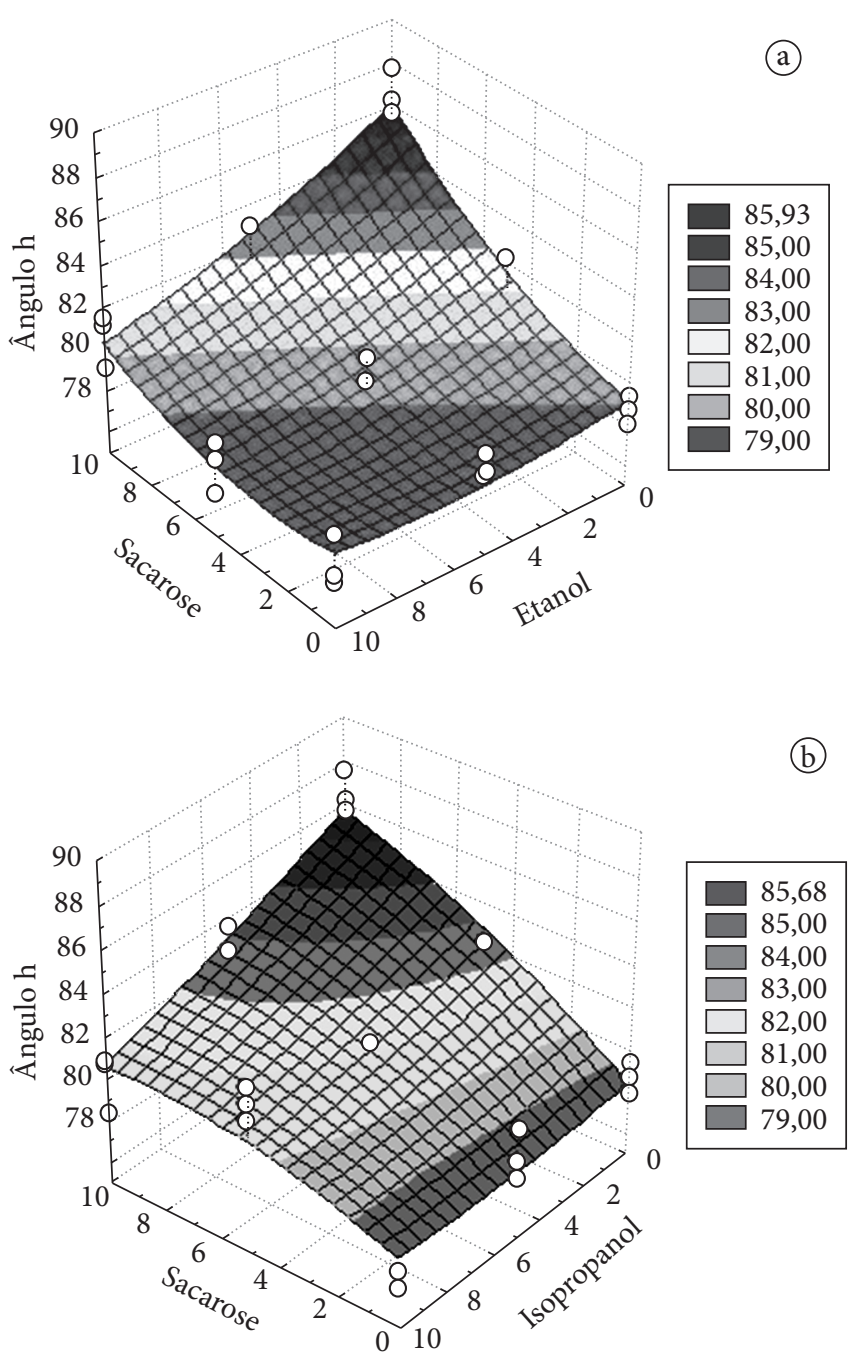

Figura 5. Superfícies de resposta para o parâmetro ângulo da tonalidade $\left(h^{\circ}\right)$ da análise de cor dos pós obtidos da polpa de pequi liofilizada em função da concentração de sacarose e da concentração de: a) etanol $\left(\mathrm{r}^{2}=86,0 \%\right) ; \mathrm{e}$ b) isopropanol $\left(\mathrm{r}^{2}=78,3 \%\right)$.

Não houve nenhuma significância dos fatores do planejamento experimental sobre o parâmetro $\Delta \mathrm{E}^{\star}$ para os sistemas sacarose-isopropanol, frutose-etanol e frutose-isopropanol.

O parâmetro ângulo da cor, ângulo da tonalidade ou ângulo de Hue $\left(h^{\circ}\right)$ foi significativamente influenciado pela interação concentração de sacarose $x$ concentração de álcool $(\mathrm{p}<0,01)$ nos sistemas sacarose-etanol e pela concentração de sacarose ( $\mathrm{p}<0,01)$ nos sistemas sacarose-isopropanol. Nos sistemas frutose-etanol e frutose-isopropanol, não houve significância ( $\mathrm{p}>0,05)$ dos tratamentos sobre este parâmetro.

Para a análise do ângulo de tonalidade, o ângulo $\mathrm{h}^{\circ}=0^{\circ}$ é fixado no eixo horizontal com a+ (vermelho) e, girando no sentido anti-horário, tem-se, $\mathrm{h}^{\circ}=90^{\circ}$ (amarelo), $\mathrm{h}^{\circ}=180^{\circ}$ (verde) $\mathrm{e} \mathrm{h}^{\circ}=270^{\circ}$ (azul). $\mathrm{O} \mathrm{h}^{\circ}$ entre $0^{\circ}$ e $90^{\circ}$ caracteriza a qualidade da cor de vermelho a amarelo. Quanto mais próximo o ângulo $h^{\circ} \mathrm{de}$ $90^{\circ}$ (amarelo), maior a perda da cor alaranjada típica do pequi.
Observa-se nas superfícies de resposta da Figura 5 que os maiores valores para o ângulo $h^{\circ}$ estão relacionados a altas concentrações de sacarose e os menores valores a altas concentrações de alcoóis. Este comportamento indica que a coloração alaranjada característica do alto teor de carotenóides e apreciada no pequi é mais bem preservada nos pós liofilizados submetidos a prétratamentos com altas concentrações de alcoóis. Nos sistemas constituídos de sacarose e etanol existe um efeito interativo entre esses fatores que contribui para os fenômenos observados.

Os alcoóis (etanol e isopropanol) e os açúcares (frutose e sacarose) propositalmente foram selecionados devido às diferenças em suas estruturas químicas. As diferenças estão no número de radicais livres expostos na estéreo-química e se a estrutura é de cadeia linear ou ramificada. Um estudo mais detalhado dos modelos de interação química entre os sistemas seria necessário para elucidar os mecanismos.

\subsection{Microscopia fotônica}

A Figura 6 mostra fotomicrografias obtidas por microscópio fotônico dos pós obtidos da polpa de pequi liofilizada submetidos a pré-tratamentos com sacarose $10 \%$, em concentrações de 0, 5 e 10\% de cada álcool. Na Figura 7, são apresentados sistemas constituídos de frutose em concentração de 10\% e, na Figura 8, tratamentos sem açúcares.

Nas estruturas mostradas na Figuras 6, observa-se maior grau de organização da microestrutura, predominando o estado cristalino (CR), principalmente quando os sistemas constituídos de sacarose são adicionados de etanol.

$\mathrm{O}$ estado cristalino (CR) caracteriza-se por estruturas tridimensionais ordenadas de moléculas, na qual há periodicidade, superfícies (faces) planas e simetria. Tais estruturas foram visíveis, por meio da microscopia fotônica, nos tratamentos constituídos de sacarose.

A cristalização nas amostras com sacarose foi mais pronunciada com altas concentrações do açúcar, principalmente, na presença de alcoóis. A sacarose, neste caso, estaria atuando como núcleos no processo de cristalização (JANCIC; GROOSTSCHOLTEN, 1984). Os alcoóis atuam como meio de indução para a cristalização dos açúcares, uma vez que promovem a supersaturação do sistema (ALMEIDA; CAL-VIDAL, 1997). Contudo, a velocidade do crescimento do cristal e o processo de cristalização dependem também das concentrações dos componentes envolvidos. O fenômeno é observado quando se usa a mesma concentração de álcool e a concentração do açúcar é aumentada ou vice-versa.

A adição de álcool à polpa de pequi para a produção dos pós liofilizados faz com que as moléculas de água e álcool tenham maior interação, promovida por intermédio das ligações de hidrogênio. Com isso, a interação da água com a sacarose, que pode ser tanto dipolo-dipolo como ligação de hidrogênio, fica enfraquecida, pois ocorre um tipo de "competição", devido ao "fortalecimento" das interações água-etanol em relação à água e ao açúcar, o que diminui, parcialmente, a solubilidade desse carboidrato, facilitando a sua cristalização (CARLOS, RESENDE; CAL-VIDAL, 2005). 

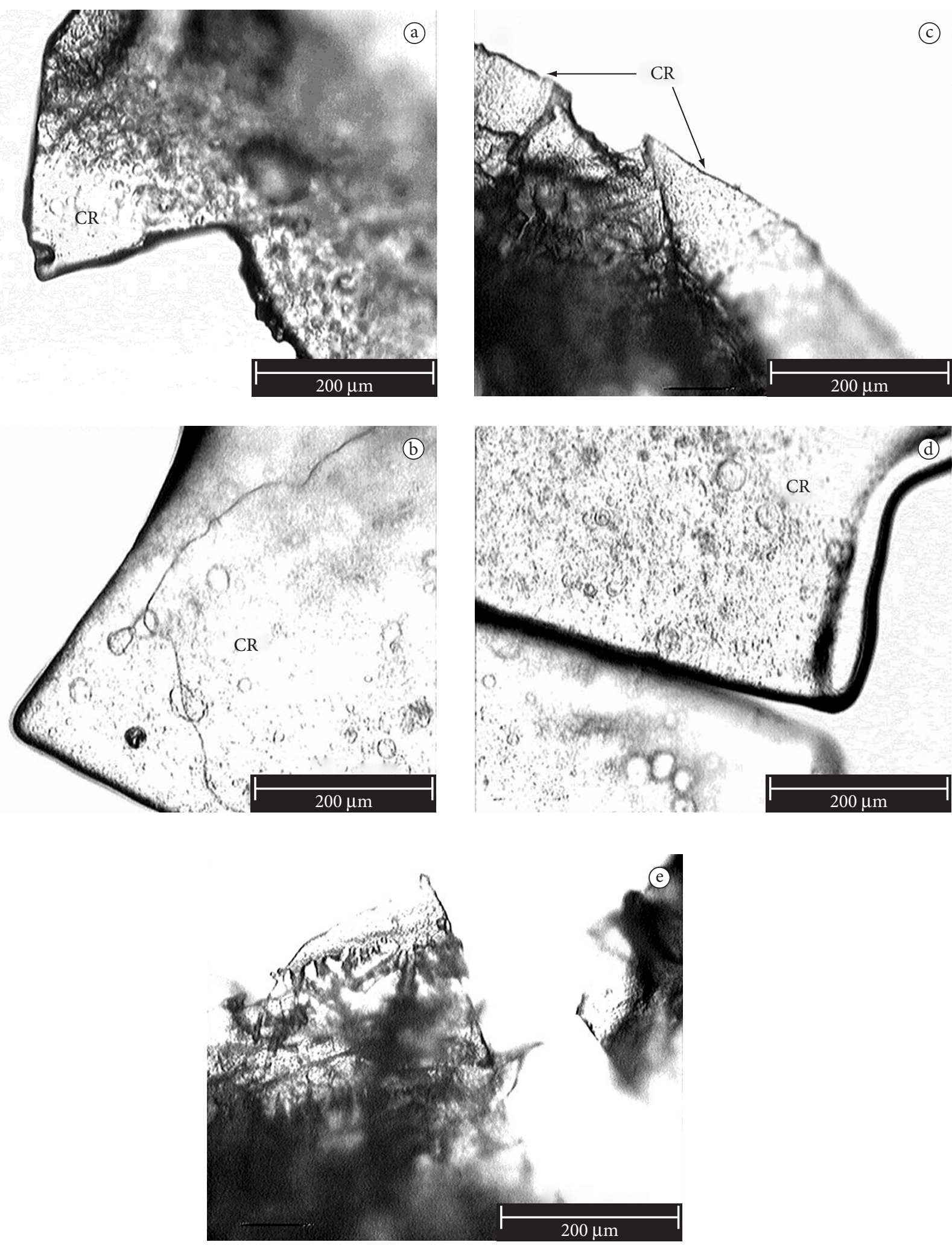

Figura 6. Fotomicrografias, em microscópio fotônico, dos tratamentos com sacarose $10 \%$ dos pós obtidos da polpa de pequi liofilizada, adicionados de: a) $0 \%$ de álcool; b) $5 \%$ de etanol; c) $10 \%$ de etanol; d) $5 \%$ de isopropanol; e e) $10 \%$ isopropanol. CR = estado cristalino.

Estruturas amorfas (AM) podem ser visualizadas em sistemas constituídos de frutose (Figura 7) e em sistemas com ausência de açúcares (Figura 8). Estas estruturas são caracteri- zadas por um estado desordenado em que não há repetição de formas geométricas e presença de faces planas bem estabelecidas. Estruturas amorfas são comuns em produtos liofilizados. 

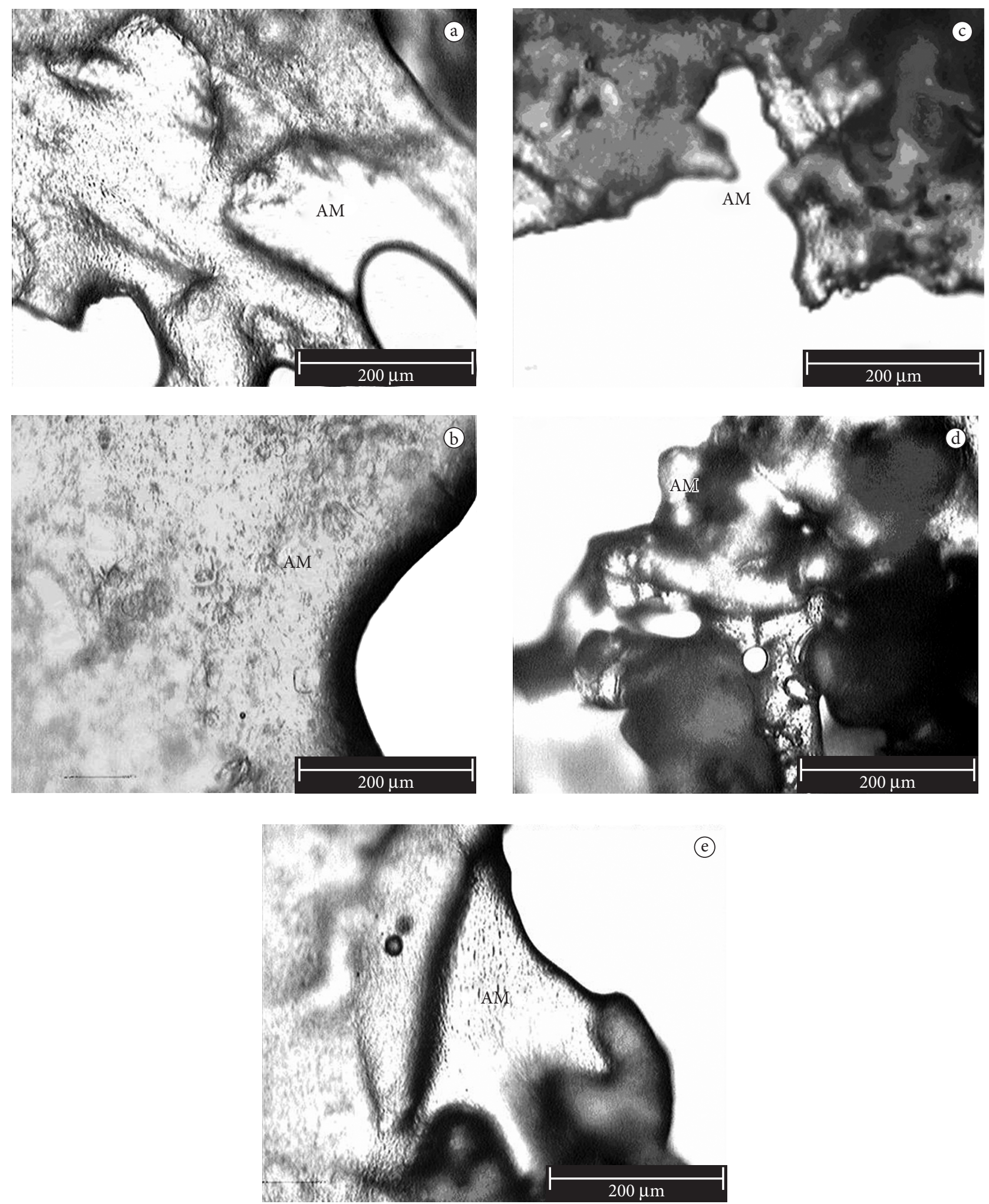

Figura 7. Fotomicrografias, em microscópio fotônico, dos tratamentos com frutose $10 \%$ dos pós obtidos da polpa de pequi liofilizada, adicionados de: a) $0 \%$ de álcool; b) 5\% de etanol; c) 10\% de etanol; d) 5\% de isopropanol; e e) 10\% isopropanol. AM = estado amorfo.

\section{Conclusões}

A miscibilidade dos alcoóis auxilia na retenção de carotenóides dos pós obtidos da polpa de pequi liofilizada, e a presença do açúcar interfere negativamente neste processo.
A concentração de sacarose é o único fator que influencia significativamente a diferença total de cor dos pós de pequi liofilizados em relação à cor da polpa original. As maiores diferenças são observadas com altas concentrações de sacarose e as 

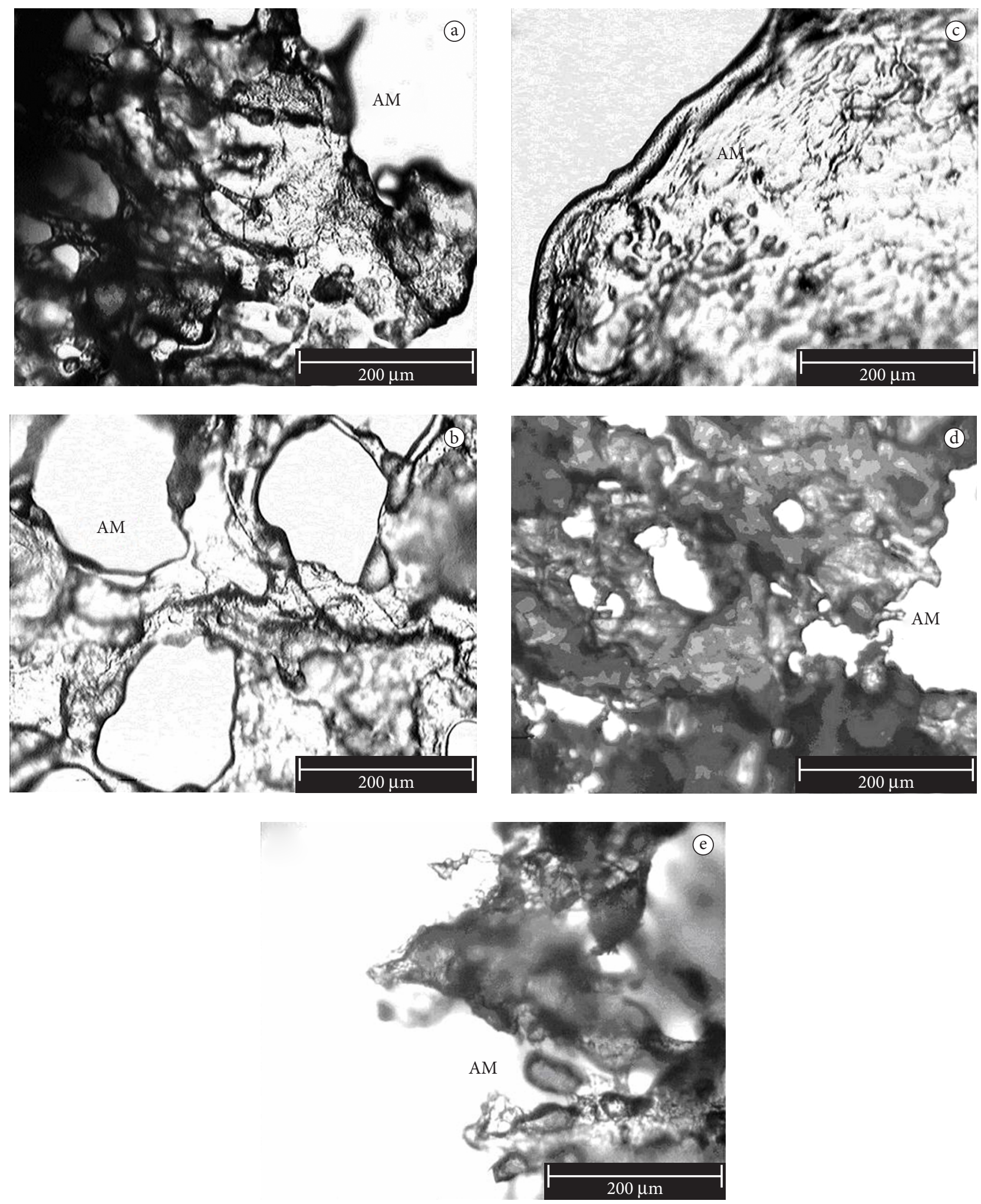

Figura 8. Fotomicrografias, em microscópio fotônico, dos tratamentos sem adição de açúcares dos pós obtidos da polpa de pequi liofilizada, adicionados de: a) $0 \%$ de álcool; b) 5\% de etanol; c) 10\% de etanol; d) 5\% de isopropanol; e e) 10\% isopropanol. AM = estado amorfo.

menores com altas concentrações de etanol, nas quais se verifica maior preservação do teor de carotenóides. Para os sistemas sacarose-isopropanol, frutose-etanol e frutose-isopropanol, as análises estatísticas não levaram a resultados conclusivos.
Os valores do ângulo $h^{\circ}$ mais próximos de $90^{\circ}$ (amarelo) também estão relacionados a altas concentrações de sacarose e os menores valores em relação ao ângulo de $90^{\circ}$ (alaranjado) a altas concentrações de alcoóis. Os resultados mostram que a 
coloração alaranjada característica do alto teor de carotenóides e apreciada no pequi é mais bem preservada nos pós liofilizados submetidos a pré-tratamentos com altas concentrações de alcoóis.

Os tratamentos com formação de estruturas cristalinas foram aqueles constituídos de sacarose. A presença destas estruturas foi mais freqüente em maiores concentrações do açúcar e, principalmente, na presença de alcoóis. Os tratamentos constituídos de frutose, com ou sem adição de alcoóis e os tratamentos sem adição de açúcares, com presença ou não de alcoóis, apresentaram pós liofilizados tipicamente amorfos.

Dentre os tratamentos pesquisados, o sistema constituído de sacarose $5 \%$, adicionado de etanol $10 \%$, é o indicado para produzir pós liofilizados obtidos da polpa de pequi com maior estabilidade durante o armazenamento. Isso se deve ao fato de apresentar estruturas tipicamente cristalinas (sem formação de pontes líquidas - caking) e, ainda, por apresentar retenção de carotenóides após o processamento.

\section{Referências bibliográficas}

ALMEIDA, L.; CAL-VIDAL, J. Fruit sugar crystallisation during freezing to reduce the hygroscopicity of freeze-dried products in powder forms. In: JOWIT, R. Engineering \& Food at ICEF 7. Sheffield: Sheffield Academic Press, v. 1, p. 9-12, 1997.

ALMEIDA, S. P. et al. Cerrado: espécies vegetais úteis. Planaltina: EMBRAPA-CPAC, 1998. 464p.

BUNN, C. W. Cristais: seu papel na natureza e na ciência. 3 ed. William Gerson Rolim de Camargo. (Trd.). São Paulo: Ed. Nacional/USP, 1972. 293p. (Tradução de: Crystals: Their role in nature and in science).

CARLOS, L. A.; RESENDE, J. V.; CAL-VIDAL, J. Redução da higroscopicidade de pós liofilizados pela indução da cristalização em soluções-modelo de açúcares constituintes de frutas. Brazilian Journal Food Technology, v. 8, n. 2, p. 163-173, abr./jun. 2005.

GEANKOPLIS, C. J. Procesos de transporte y operaciones unitárias. 3 ed. México: Continental, 1998. 1008p.

GODOY, H. T.; RODRIGUEZ-AMAYA, D. B. Carotenoid composition of Brazilian nectarine (Prunus persica). Revista do Instituto Adolfo Lutz, n. 57, v. 1, p. 73-79, 1998. Disponível em: <http:// bases.bireme. br/cgi-bin/wxislind.exe/iah/online/>. Acesso em: 17 jul. 2006.
ILLY, A.; VIANI, R. Espresso coffee: the chemistry of quality. 2 ed. San Diego: Academic Press, 1996. 253 p.

INSTITUTO ADOLFO LUTZ. Normas analíticas do Instituto Adolfo Lutz - métodos químicos e físicos para análise de alimentos. São Paulo, 1985.

JANCIC, S. J.; GROOTSCHOLTEN, P. A. M. Nucleation: mechanisms and sources of nuclei in industrial crystallizers. In:__. Industrial crystallization. Delft: Delft University, 1984. 15-37 p. Cap. 2.

KING, C. J. Spray drying of food liquids and volatiles retention. In Bruin (Ed.). Preconcentration and drying of food materials. Amsterdam: Elsevier.

KROKIDA, M. K.; PHILIPPOPOULOS, C. Volatility of apples during air and freeze drying. Journal of Food Engineering, v. 73, n. 2, p. 135-141, 2006.

MAIA, M. C. A. Influência da adição de pectina, gelatina e ácido cítrico na higroscopicidade dos pós liofilizados de sucos cítricos. Lavras, 1988. 178p. Dissertação - (Mestrado em Ciências dos Alimentos), Universidade Federal de Lavras - UFLA.

MARQUES, M. C. S. et al. Estudo biológico dos extratos etanólicos e metanólicos de pequi. In: CONGRESSO BRASILEIRO DE FITOPATOLOGIA; CONGRESSO LATINO-AMERICANO DE FITOPATOLOGIA, 11, 2001, São Pedro. Anais... São Pedro: Fitopatologia Brasileira, 2001. v. 26, p. 332-332.

MINITAB, Minitab Inc. MINITAB release 14 for Windows, 2003. Disponível em: <http://www.minitabbrasil.com.br>.

MINOLTA. Precise color communication: color control from perception to instrumentation. Sakai, 1998. (encarte).

RIBEIRO, R. F. Pequi: o rei do cerrado. Belo Horizonte: Rede Cerrado, 2000. 62p.

RODRIGUEZ-AMAYA, D. B. Nature and distribution of carotenoids in foods. In: CHATALAMBOUS, F. (Ed.). Shelf life of foods and beverages - chemical, biological, physical and nutritional aspects. Amsterdam: Elsevier Science, 1993. p. 547-589.

RODRIGUEZ-AMAYA, D. B. A guide to carotenoid analysis in food. Washington: ILSI Press, 2001. 64p.

SHIMIZU, M. K. et al. Avaliação do efeito de diferentes concentrações de álcool na destanização e amadurecimento de caqui. Agronomia, v. 36, n. 1-2, p. 11-16, 2002.

SING, R. K. et al. $\alpha$-lactose monohydrate from ultrafiltered whey permeate in one step crystallization using ethanol-water mixtures. Journal of Food Science, v. 6, n. 3, p. 777-781, 1991.

STATISTICA. Statistica 7.0, EUA Software. Tucksa: StatSof, 2005. 